\title{
Signaling pathways involved in the effects of HMGB1 on mesenchymal stem cell migration and osteoblastic differentiation
}

\author{
FENG LIN*, WEI ZHANG* , DETING XUE, TING ZHU, JIN LI, ERMAN CHEN, XUEYU YAO and ZHIJUN PAN \\ Department of Orthopedics, Second Affiliated Hospital, School of Medicine, \\ Zhejiang University, Hangzhou, Zhejiang 310009, P.R. China
}

Received February 13, 2015; Accepted December 28, 2015

DOI: 10.3892/ijmm.2016.2479

\begin{abstract}
High mobility group box 1 (HMGB1) epxression has been found in the inflammatory microenvironment of fractures. It is well known that HMGB1 acts as a chemoattractant for mesenchymal stem cells (MSCs); however, the effects of HMGB1 on MSC migration and osteoblastic differentiation, and the signaling pathways involved in these effects, have not yet been elucidated. In this study, we aimed to investigate these effects, as well as the signaling mechanisms involved, using in vitro models. We found that HMGB1, in varying concentrations, promoted the osteoblastic differentiation of MSCs, the synthesis of receptor for advanced glycation end products (RAGE) and Toll-like receptor (TLR)2/4, and the activation of the $\mathrm{p} 38$ mitogen-activated protein kinase (MAPK) and nuclear factor $-\kappa \mathrm{B}(\mathrm{NF}-\kappa \mathrm{B})$ signaling pathways. Subsequently, we cultured the MSCs in the appropriate concentration of HMGB1, and determined the signaling pathways involved in the effects of HMGB1 on MSC migration and differentiation, using receptor neutralizing antibodies and signaling pathway inhibitors. From the results of this study, we concluded that HMGB1 promotes MSC migration through the activation of the p38 MAPK signaling pathway, and also promotes MSC differentiation by binding to TLR $2 / 4$ and activating the p38 MAPK signaling pathway. These findings elucidate the mechanisms underlying the effects of HMGB1 in the fracture microenvironment, which may provide a theoretical basis for the development of improved clinical treatments for fractures.
\end{abstract}

\section{Introduction}

High mobility group box 1 (HMGB1) was initially characterized as a non-histone nucleoprotein; it is an ubiquitously

Correspondence to: Dr Zhijun Pan, Department of Orthopedics, Second Affiliated Hospital, School of Medicine, Zhejiang University, 88 Jiefang Road, Hangzhou, Zhejiang 310009, P.R. China

E-mail: zepzj@163.com

*Contributed equally

Key words: mesenchymal stem cells, high mobility group box 1, migration, osteoblastic differentiation, signaling pathways expressed, highly conserved DNA-binding protein. It regulates gene transcription, stabilizes the structure of nucleosomes, mediates inflammation, and facilitates nerve growth and tumor metastasis. It is localized in the nucleus, but HMGB1 is also found in the cytoplasm and membrane of various cells (1-4).

Mesenchymal stem cells (MSCs) are one of the primary stem cell populations involved in fracture repair; their migration into the fracture microenvironment and osteogenic differentiation play an important role in healing (5). Previous studies have suggested that inflammatory factors released by necrotic cells play a significant role in MSC migration and differentiation in the inflammatory microenvironment of fractures (6,7). HMGB1 is released into the extracellular space when it is secreted from active cells and is passively released from necrotic cells following a fracture, resulting in a marked increase in the concentration of HMGB1 outside cells (8).

It is well known that HMGB1 acts as a chemoattractant for MSCs (9). In the fracture microenvironment, the expression of almost all HMGB1 receptors is significantly upregulated, including the receptor for advanced glycation end products (RAGE), Toll-like receptor (TLR)2 and TLR4. RAGE is currently understood to be the main high-affinity receptor for HMGB1 (10). When HMGB1 binds to RAGE, the mitogen-activated protein kinase (MAPK) signaling pathway is activated (11). It has been shown that the p38 MAPK signaling pathway plays an important role in the osteoblastic differentiation of MSCs (12). Moreover, the intracellular nuclear factor $-\kappa B(N F-\kappa B)$ pathway, mediated by TLR2/4 (10), is known to facilitate cell proliferation and differentiation $(10,13,14)$.

To date, it remains unknown as to whether HMGB1 promotes the differentiation of MSCs, and which of the aforementioned signal transduction pathways may be involved in any effect of HMGB1 on MSCs. Thus, in the present study, we investigated the role that extracellular HMGB1 plays in promoting the differentiation of MSCs. Furthermore, the extracellular receptors and intracellular signaling pathways that mediate the promotion of MSC differentiation by HMGB1 were investigated, using receptor neutralizing antibodies and signaling pathway inhibitors.

\section{Materials and methods}

Reagents. Recombinant human HMGB1 protein was purchased from Sigma (St. Louis, MO, USA). Graded concentrations of HMGB1, ranging from 12.5 to $200 \mathrm{ng} / \mathrm{ml}$, were used in the 
experiments described below, as serum levels of HMGB1 in septic patients have previously been reported to be approximately 30-150 ng/ml (15). For RAGE receptor blocking, RAGE neutralizing antibody (No. Q15109; R\&D Systems, Minneapolis, MN, USA) was used at the concentration of $5 \mu \mathrm{g} / \mathrm{ml}$, for TLR2 receptor blocking, TLR2 neutralizing antibody (No. O60603; R\&D Systems) was used at the concentration of $0.5 \mu \mathrm{g} / \mathrm{ml}$ and for TLR4 receptor blocking, TLR4 neutralizing antibody (No. O00206; R\&D Systems) was used at the concentration of $1.5 \mu \mathrm{g} / \mathrm{ml} . \mathrm{p} 38$ inhibitor (SB203580; Cell Signaling Technology, Inc., Danvers, MA, USA) was used at the concentration of $0.5 \mu \mathrm{M}$, and NF- $\mathrm{KB}$ inhibitor (BAY 11-7082; Cell Signaling Technology, Inc.) was used at the concentration of $0.1 \mu \mathrm{M}$. All of the above-mentioned reagents were used according to the respective manufacturer's instructions.

Culture and expansion of human bone marrow-derived MSCs. MSCs were purchased from Cyagen Biosciences, Inc. (Guangzhou, China). The MSCs were trypsinized and passaged after the cell confluence reached approximately $80 \%$, and cells at passage 3-5 were used in the experiments described below.

Transwell migration assay. Cell migration was examined using Transwell chambers (pore size, $8 \mu \mathrm{m}$ diameter; Corning Costar, Acton, MA, USA). Complete medium containing $0.1 \%$ fetal calf serum (FCS) was added to the wells of a 24-well plate, and serum-starved $1 \times 10^{5}$ MSCs were then suspended in a volume of $100 \mu \mathrm{l}$ complete medium containing $0.1 \%$ FCS were added to the upper chamber. Prior to the addition of HMGB1, the Transwell plate (with MSCs in the upper chamber and medium containing $0.1 \%$ FCS only in the lower chamber) was first incubated at $37^{\circ} \mathrm{C}$ for $1 \mathrm{~h}$. Following the addition of HMGB1, the plate was incubated at $37^{\circ} \mathrm{C}$ for $3 \mathrm{~h}$, followed by membrane fixation with $4 \%$ paraformaldehyde and staining with $0.1 \%$ crystal violet (both from Cyagen Biosciences (Guangzhou) Inc., Guangzhou, China. The membranes were then washed, and the cells on the underside of the membranes were observed under a light microscope (Leica DMI LM; Leica Microsystems, Wetzlar, Germany). Subsequently, the numbers of cells were counted in 5-10 random fields for each membrane.

Assays for osteogenic differentiation. In order to induce osteogenic differentiation, the cells were cultured in standard osteoinductive (OSI) medium containing $0.1 \mu \mathrm{M}$ dexamethasone (DEX), $10 \mathrm{mM}$ glycerophosphate disodium and $0.5 \mathrm{mM}$ ascorbic acid (Sigma), as previously described (16). In addition, HMGB1- and RAGE-blocking antibodies, TLR2/4 receptor-blocking antibody and $\mathrm{p} 38$ and NF- $\mathrm{KB}$ inhibitors in some instances were utilized in OSI medium in order to observe the osteoinductive effects of HMGB1.

Total RNA extraction and reverse transcription-quantitative polymerase chain reaction (RT-qPCR). In order to observe MSC differentiation following exposure to HMGB1, the cells were cultured in osteogenic induction medium (Cyagen Biosciences, Inc.) or HMGB-1 at $50 \mathrm{ng} / \mathrm{ml}$ for 5 days. Total RNA was extracted using TRIzol reagent (Invitrogen Life Technologies, Carlsbad, CA, USA) according to the manufacturer's instructions. RT-qPCR) was carried out in order to observe the expression of osteoblastic markers. Quantitative PCR (qPCR)
Table I. Primers used for RT-qPCR.

\begin{tabular}{ll}
\hline Gene name & \multicolumn{1}{c}{ Primer } \\
\hline OSTERIX & F: 5'-CCTGCGACTGCCCTAATT-3' \\
& R: 5'-GCGAAGCCTTGCCATACA-3' \\
BMP-2 & F: 5'-CATGCCATTGTTCAGACG-3' \\
& R: 5'-TGTACTAGCGACACCCAC-3' \\
ALP & F: 5'-TTGACCTCCTCGGAAGACACTCTG-3' \\
& R:5'-CGCCTGGTAGTTGTTGTGAGCATAG-3' \\
RAGE & F: 5'-TGTGTGGCCACCCATTCCA-3' \\
& R: 5'-TGTGTGGCCACCCATTCCA-3' \\
TLR2 & F: 5'-TGACTCCCAGGAGCTCTTAG-3' \\
& R: 5'-CTTCCTTGGAGAGGCTGATG-3' \\
TLR4 & F: 5'-CCTGGACCTGAGCTTTAATC-3' \\
& R: 5'-AAAGGCTCCCAGGGCTAAAC-3' \\
GAPDH & F: 5'-TGACGCTGGGGCTGGCATTG-3' \\
& R: 5'-GGCTGGTGGTCCAGGGGTCT-3' \\
\hline
\end{tabular}

F, forward; R, reverse.

was carried out using a StepOnePlus Real-Time PCR system and SYBR-Green reagents (Roche Diagnostics, Indianapolis, IN, USA) as a double-strand DNA-specific binding dye. Primers of the selected genes selected for PCR reactions were synthesized as shown in Table I. PCR reactions were performed in triplicate for each run. The mRNA expression levels of target genes and the housekeeping gene, GAPDH, were quantified in separate tubes. The cycling conditions were as follows: $95^{\circ} \mathrm{C}$ for $30 \mathrm{sec}$ and 40 cycles of $95^{\circ} \mathrm{C}$ for $5 \mathrm{sec}, 60^{\circ} \mathrm{C}$ for $35 \mathrm{sec}$. The value of $2^{-\Delta \mathrm{Cl}}$ represents the relative level of target gene expression.

Alkaline phosphatase (ALP) and Alizarin red staining. The human MSCs $\left(10^{4} / \mathrm{cm}^{2}\right)$ were seeded into 24-well plates and cultured in osteogenic induction medium (Cyagen Biosciences, Inc.). After 7 days, ALP activity was assayed using a BCIP/NBT Alkaline Phosphatase Color Development kit (Beyotime Biotech, Jiangsu, China). DAPI (Beyotime Biotech) was used to stain the nuclei. The ALP-positive cells were counted under a light microscope (Leica DMI LM) in 5 randomly selected fields. Calcium deposits were detected by staining with 2\% Alizarin red (pH 4.2; Sigma). To quantify the number of stained nodules, the stain was solubilized with $0.5 \mathrm{ml}$ $5 \%$ sodium dodecyl sulphate (SDS) in $0.5 \mathrm{~N} \mathrm{HCl}$ for $30 \mathrm{~min}$ at room temperature. The solubilized stain $(0.15 \mathrm{ml})$ was transferred to the wells of a 96-well plate, and the absorbance was measured at $405 \mathrm{~nm}$. Data are presented as the means $\pm S D, n=3$.

Western blot analysis. The cells were harvested and lysed in RIPA buffer containing protease inhibitors. After measuring the concentration, protein samples were separated by $10 \%$ SDS-polyacrylamide gel electrophoresis (SDS-PAGE) and transferred onto polyvinylidene difluoride (PVDF) membranes (Millipore, Billerica, MA, USA). The membranes were blocked in 5\% skim milk for $1 \mathrm{~h}$ and incubated with antibodies against ALP (sc-98652; Santa Cruz Biotechnology, Inc., 

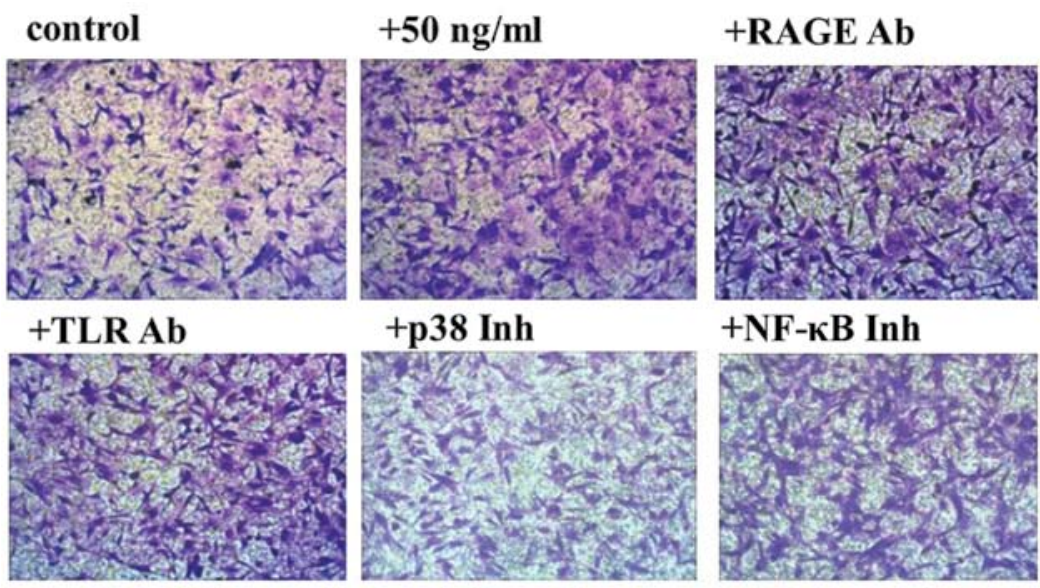

+ p38 Inh

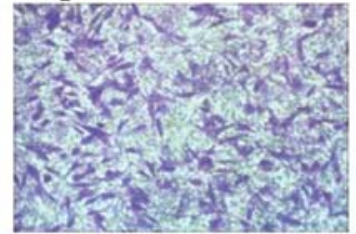

$+\mathrm{NF}-\kappa \mathrm{B}$ Inh

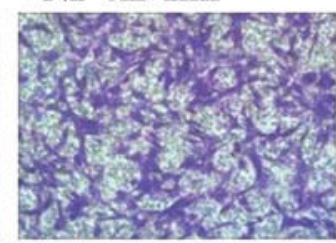

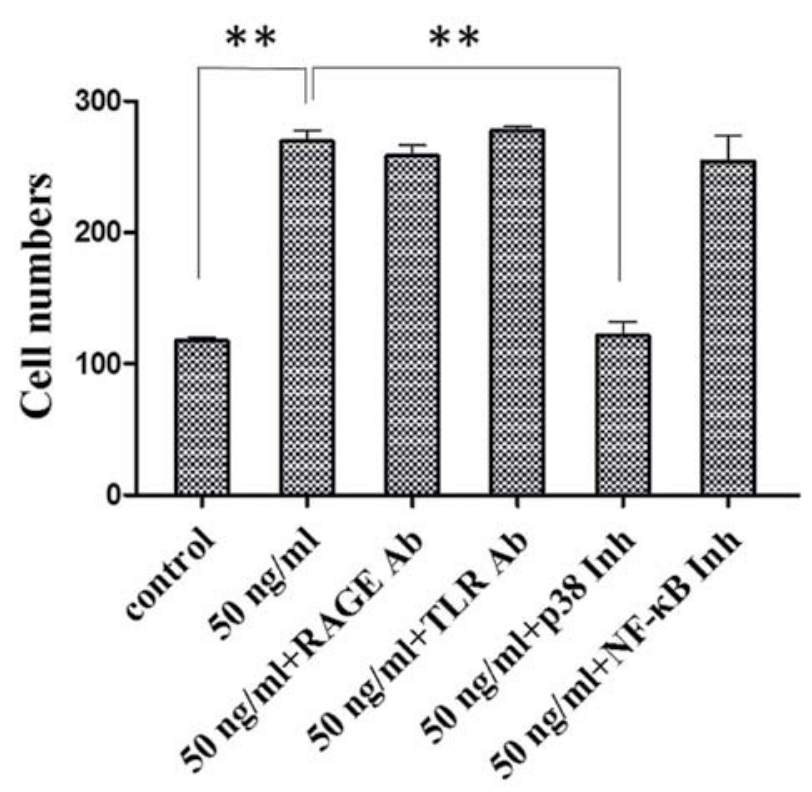

Figure 1. High mobility group box 1 (HMGB1) promotes the migration of mesenchymal stem cells (MSCs). Migration of MSCs is altered by treatment with a p38 inhibitor (Inh). Results were obtained from 3 independent experiments and are expressed as the means \pm SD ( $n=3$ in each experiment). RAGE, receptor for advanced glycation end products; Ab, antibody; TLR, Toll-like receptor; NF- $\kappa \mathrm{B}$, nuclear factor- $\kappa \mathrm{B} .{ }^{* *} \mathrm{P}<0.01$.

Santa Cruz, CA, USA), OSTERIX (ab94744; Abcam, Cambridge, MA, USA), bone morphogenetic protein-2 (BMP-2; sc-6895; Santa Cruz Biotechnology, Inc.), RAGE (ab3611; Abcam), TLR2 (sc-10739), TLR4 (sc-293072) (both from Santa Cruz Biotechnology, Inc.), p38 (\#9212), phosphorylated (p-)p38 (9215) (both from Cell Signaling Technology, Inc.), NF-кB (sc-372; Santa Cruz Biotechnology, Inc.), p-NF-кB (\#3039; Cell Signaling Technology, Inc.) and $\beta$-actin (sc-130301; Santa Cruz Biotechnology, Inc.) separately at $4^{\circ} \mathrm{C}$ overnight. Following incubation with peroxidase-linked secondary antibodies, immunoreactive proteins were visualized with ECL reagent (Thermo Fisher Scientific, Inc., Waltham, MA, USA). The relative quantification of the bands was performed using Image $\mathrm{J}$ software.

Statistical analysis. Statistical significance was determined using a two-tailed Student's t-test, assuming equal variances. The Chi-square test was used to compare rates. P-values $<0.05$, and $<0.01$ were considered to indicate statistically significant differences.

\section{Results}

Effects of HMGB1 on the migration of MSCs. Following treatment with HMGB1 at a concentration of $50 \mathrm{ng} / \mathrm{ml}$, there was a significant increase in the number of migrating cells compared to the untreated control group (Fig. 1). The cells were treated with HMGB1 $(50 \mathrm{ng} / \mathrm{ml})$ and either RAGE neutralizing antibody (Fig. 1; $50 \mathrm{ng} / \mathrm{ml}+$ RAGE Ab), TLR2/4 neutralizing antibody (Fig. 1;50 ng/ml + TLR Ab), or NF-אB inhibitor (Fig. 1; $50 \mathrm{ng} / \mathrm{ml}+\mathrm{NF}-\mathrm{\kappa B}$ Inh). In each case, there was a significant increase in cell migration compared to the untreated control group; however, the difference was not significant compared to the cells treated with HMGB1 alone. There was a decrease in the number of migrating cells in the p38 inhibitor-treated group (Fig. 1; $50 \mathrm{ng} / \mathrm{ml}+\mathrm{p} 38 \mathrm{Inh}$ ) compared to the population of cells treated with HMGB1 alone.

Effects of HMGBI on the osteoblastic differentiation of MSCs. Alizarin red staining and quantitative analysis revealed 
A
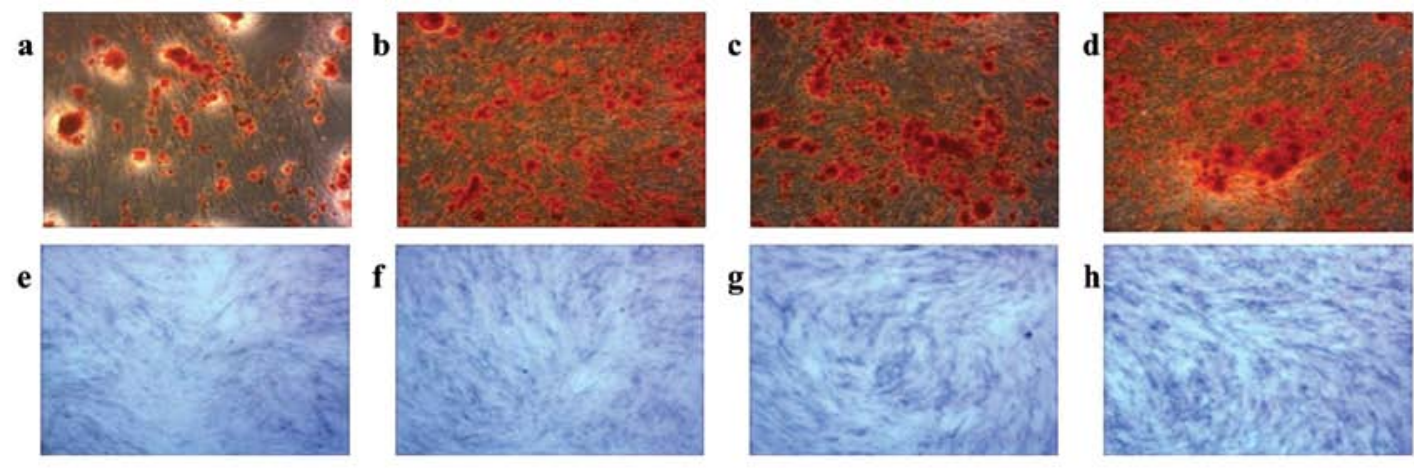

B

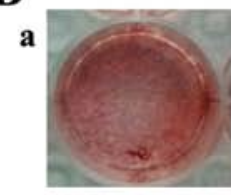

e

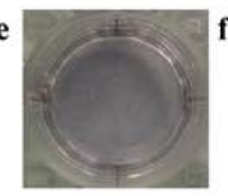

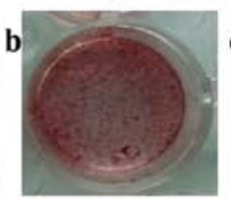

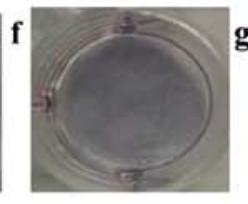

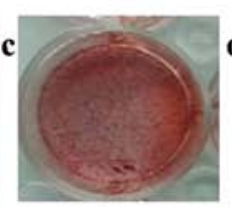

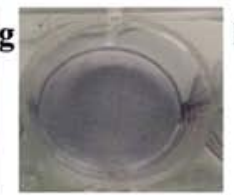

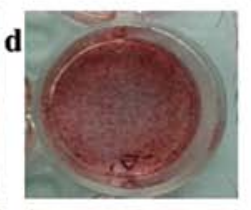

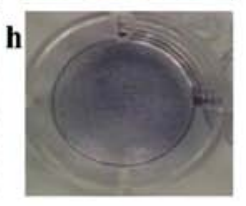

C Alizarin red

ALP

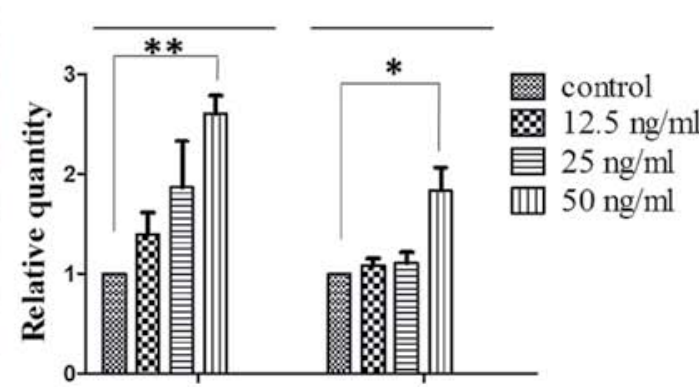

Figure 2. High mobility group box 1 (HMGB1) promotes the formation of calcified nodules and alkaline phosphatase (ALP) activity. Mesenchymal stem cells (MSCs) were maintained in standard osteoinductive (OSI) complete medium alone (A and B, panel a) or with HMGB1 (A and B, panels b-d: $12.5,25$ and 50 ng/ ml, respectively) for 14 days. Cells were stained with Alizarin red (A and B, panels a-d). MSCs were maintained in OSI complete medium alone (A and B, panel e) or with HMGB1 (A and B, panels f-h: 12.5, 25 and $50 \mathrm{ng} / \mathrm{ml}$, respectively) for 7 days. Cells were stained with Alizarin red (A and B, panels a-d) or with ALP (A and B, panels e-h). The number of stained nodules and ALP activity in MSCs treated with graded concentrations of HMGB1, or OSI medium alone was quantified. (C) Results were obtained from 3 independent experiments and are expressed as the means $\pm \mathrm{SD}\left(\mathrm{n}=3\right.$ in each experiment). ${ }^{*}<0.05$ and ${ }^{* *} \mathrm{P}<0.01$.

that HMGB1 $(12.5$ to $50 \mathrm{ng} / \mathrm{ml})$ significantly promoted the formation of calcified nodules in the MSCs. Moreover, ALP staining of the MSCs (7 days) demonstrated that HMGB1 ( 12.5 to $50 \mathrm{ng} / \mathrm{ml}$ ) significantly stimulated the synthesis of ALP in the MSCs (Fig. 2).

Effects of HMGB1 on the mRNA and protein expression levels of ALP, OSTERIX and BMP-2 in MSCs. The MSCs were maintained in OSI complete medium alone (Fig. 3A, lane a) or with HMGB1 (Fig. 3A, lanes b-d: 12.5, 25 and $50 \mathrm{ng} / \mathrm{ml}$, respectively) for 3, 5 and 7 days. Western blot analysis was used to determine the extent of osteoblastic differentiation (Fig. 3B). Our results revealed that treatment with HMGB1 (12.5 to $50 \mathrm{ng} / \mathrm{ml})$ markedly increased the protein expression levels of OSTERIX, ALP and BMP-2 during the osteoblastic differentiation of MSCs. The results of RT-qPCR (24, 48 and $72 \mathrm{~h}$ ), which was used to detect the expression of the corresponding mRNA transcripts, also revealed the upregulation of gene expression in response to treatment with HMGB1 (Fig. 3C).

Effects of HMGB1 on the $m R N A$ and protein expression levels of RAGE, TLR2/4, and mediators of the p38 MAPK and $N F-\kappa B$ signaling pathways in MSCs. The MSCs were maintained in OSI complete medium alone (Fig. 4A, lane a) or with HMGB1 (Fig. 4A, lanes b-d: 12.5, 25 and $50 \mathrm{ng} / \mathrm{ml}$, respectively) for 3, 5 and 7 days. Western blot analysis was used to determine the protein expression levels of RAGE and TLR2/4 (Fig. 4C). Our results revealed that treatment with HMGB1 (12.5 andto $50 \mathrm{ng} / \mathrm{ml})$ markedly increased the expression of RAGE and TLR2/4 during the osteoblastic differentiation of MSCs. The results of RT-qPCR (24, 48 and $72 \mathrm{~h}$ ), which was used to detect expression of the corresponding mRNA transcripts, also revealed the upregulation of gene expression in response to treatment with HMGB1 (Fig. 4D).

The MSCs were maintained in OSI complete medium alone (Fig. 4B, lane a) or with HMGB1 (Fig 4B, lanes b-d: 12.5, 25 and $50 \mathrm{ng} / \mathrm{ml}$, respectively). The MSCs were also maintained in OSI complete medium with HMGB1 $(50 \mathrm{ng} / \mathrm{ml})$ and RAGE neutralizing antibody (Fig. 4B, lane e) or TLR 2/4 neutralizing antibody (Fig. 4B, lane f). There was a dose-dependent increase in the expression of p-p38 and $p-N F-\kappa B$ in response to HMGB1 treatment. Treatment with the RAGE neutralizing antibody and the TLR2/4 neutralizing antibody had no significant effect on the HMGB1-induced upregulation of p-p38 and p-NF- $\kappa$ B (Fig. 4E).

Effects of neutralizing antibodies or inhibitors on the HMGB1-induced osteoblastic differentiation of MSCs. Statistical analysis indicated that treatment of the MSCs with the TLR2/4 neutralizing antibody or p38 inhibitors attenuated the formation of calcified nodules (Fig. 5A and B, panels a-f). Similar results were observed following ALP staining (7 days) (Fig. 5A and B, panels g-1). However, treatment of the MSCs with NF- $\kappa$ B inhibitors did not significantly inhibit the formation of calcified nodules or ALP activity compared to the cells treated with $50 \mathrm{ng} / \mathrm{ml} \mathrm{HMGB1}$ alone (Fig. 5). 
A

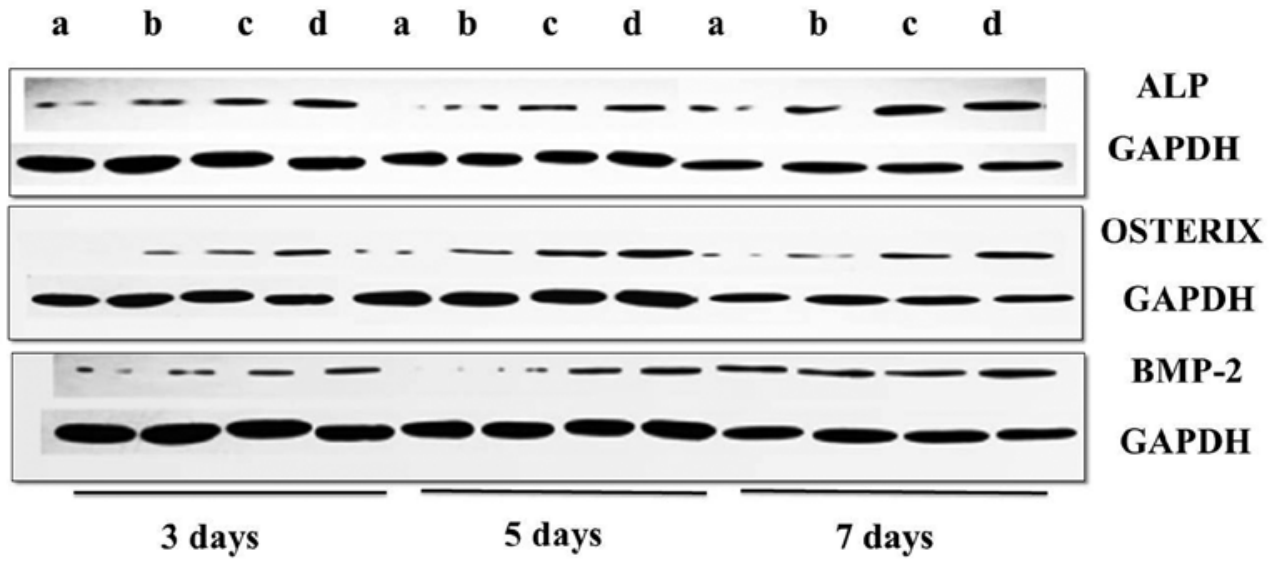

B ALP OSTERIX

BMP-2

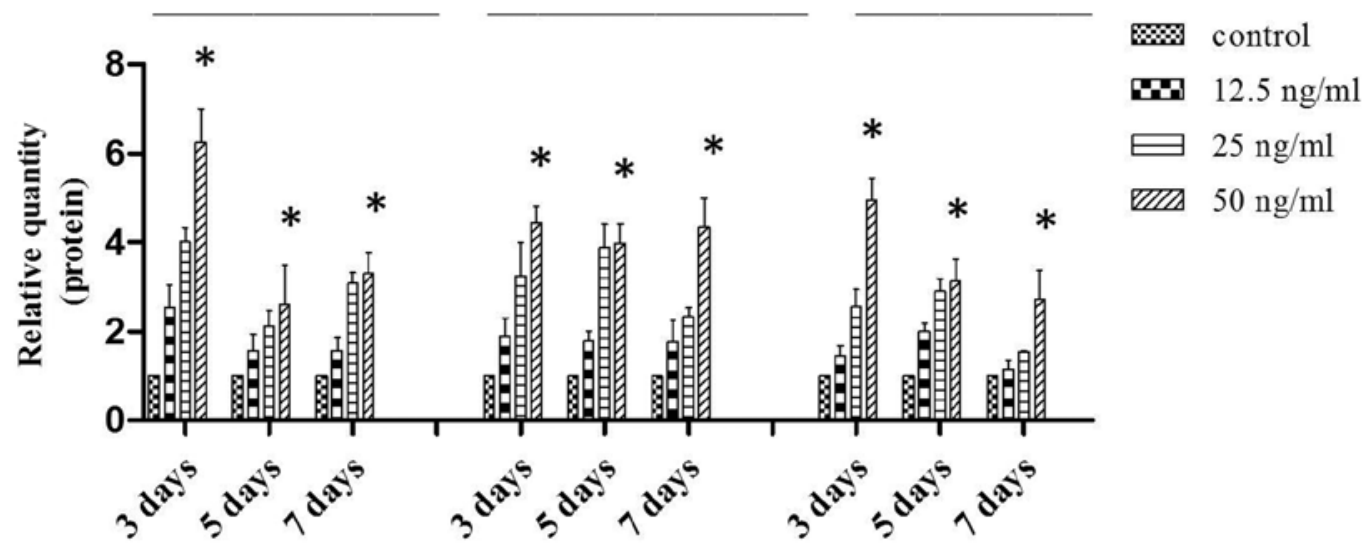

C

ALP OSTERIX BMP-2

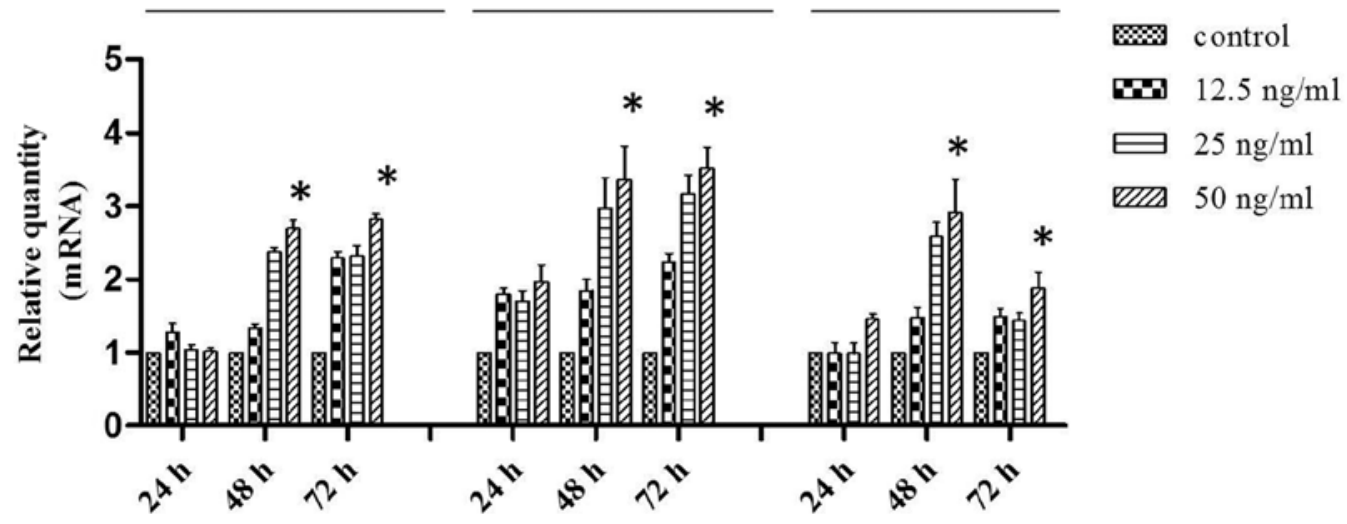

Figure 3. (A and B) High mobility group box 1 (HMGB1)-induced upregulation of OSTERIX, alkaline phosphatase (ALP) and bone morphogenetic protein-2 (BMP-2) protein expression detected by western blot analysis. The MSCs were maintained in OSI complete medium alone (A, lane a) or with HMGB1 (A, lanes b-d: $12.5,25$ and $50 \mathrm{ng} / \mathrm{ml}$, respectively) for 3, 5 and 7 days. (C) HMGB1-induced upregulation of OSTERIX, ALP and BMP-2 mRNA expression detected by RT-qPCR. Results were obtained from 3 independent experiments and are expressed as the means $\pm \mathrm{SD}\left(\mathrm{n}=3\right.$ in each experiment). ${ }^{*} \mathrm{P}<0.05$.

Effects of neutralizing antibodies or inhibitors on the HMGB1-induced upregulation of ALP, OSTERIX and BMP-2 $m R N A$ and protein expression in MSCs. Treatment of the MSCs with RAGE neutralizing antibody and $50 \mathrm{ng} / \mathrm{ml}$ HMGB1 signif- icantly altered the expression of OSTERIX, ALP and BMP-2 compared to the untreated control group, but not compared to the cells treated with HMGB1 alone. Treatment of the MSCs with TLR2/4 neutralizing antibody or $\mathrm{p} 38$ inhibitor resulted in 
A $\quad$ a

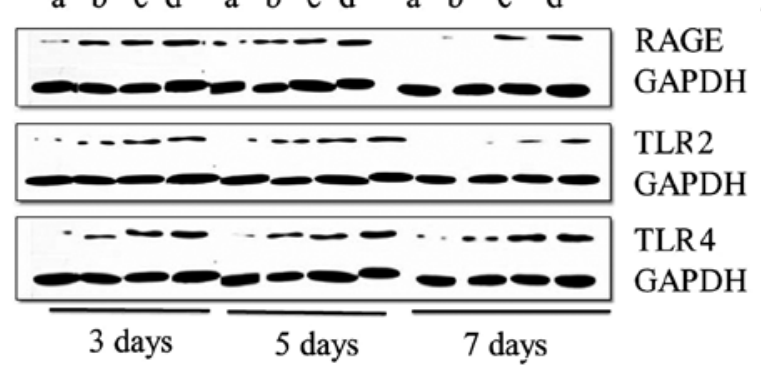

$\mathbf{C}$

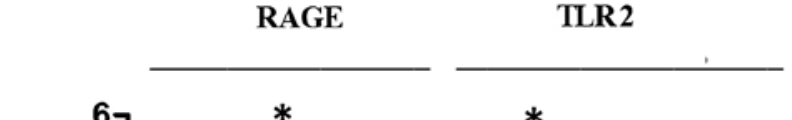

D

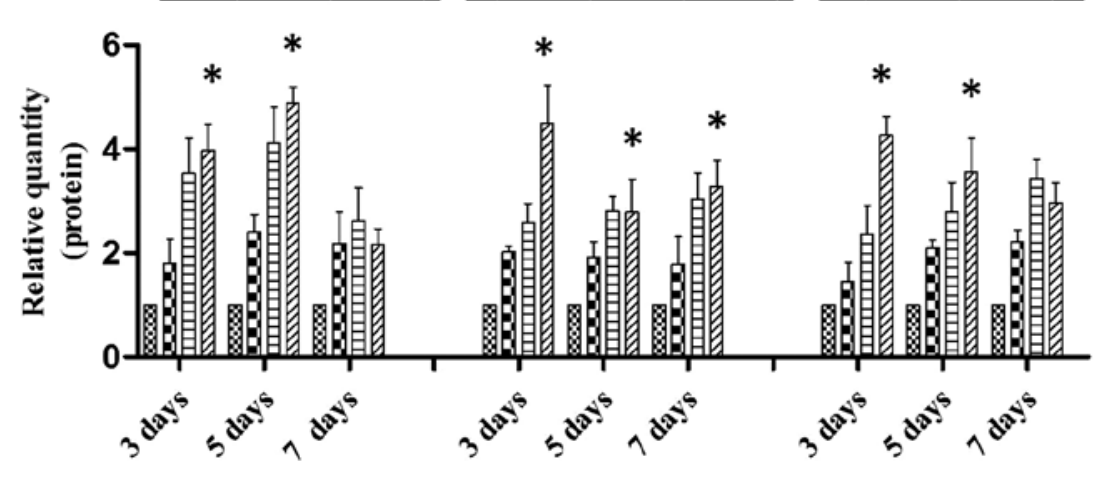

지 control

(6) $12.5 \mathrm{ng} / \mathrm{ml}$

曰 $25 \mathrm{ng} / \mathrm{ml}$

एखा $50 \mathrm{ng} / \mathrm{ml}$

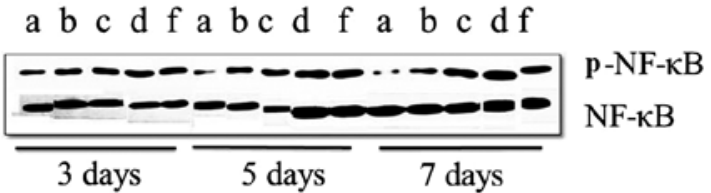

TLR4

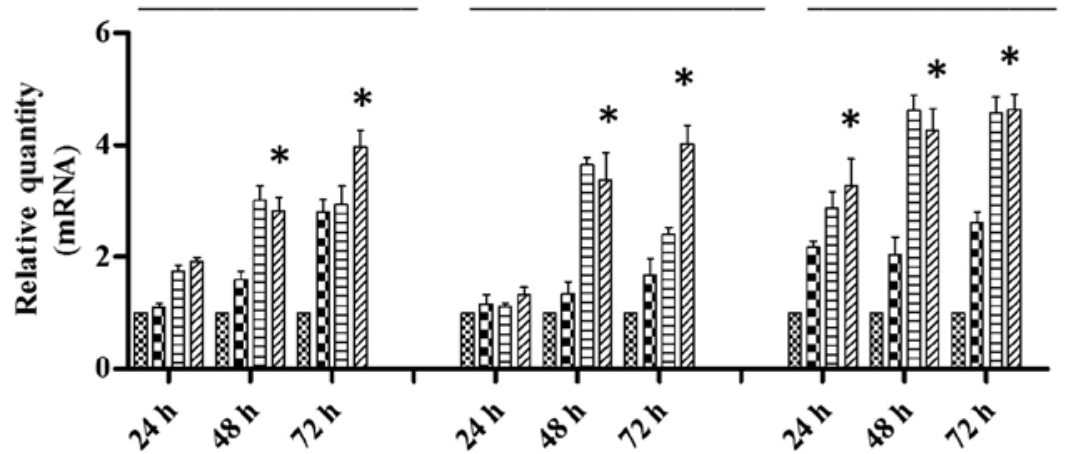

control

ED $12.5 \mathrm{ng} / \mathrm{ml}$

曰 $25 \mathrm{ng} / \mathrm{ml}$

표 $50 \mathrm{ng} / \mathrm{ml}$

$\mathbf{E}$

p-p38

$\mathrm{p}-\mathrm{NF}-\mathrm{\kappa} \mathrm{B}$

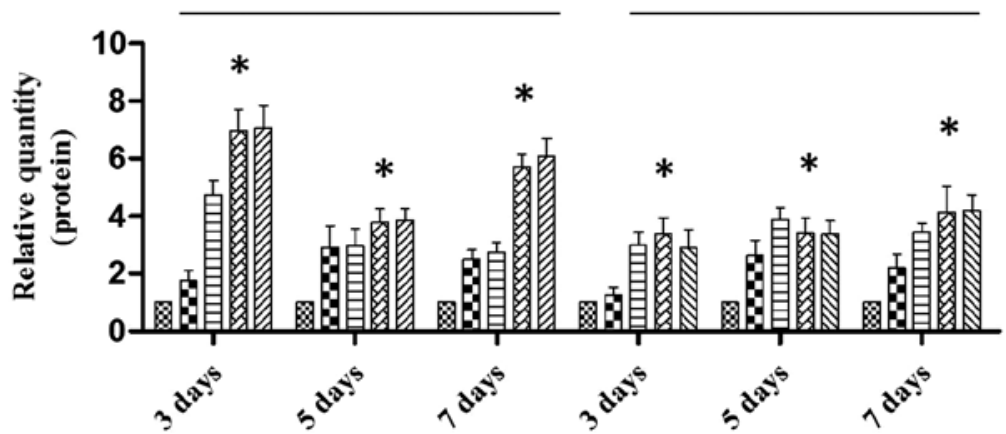

control

$12.5 \mathrm{ng} / \mathrm{ml}$

Е $25 \mathrm{ng} / \mathrm{ml}$

$50 \mathrm{ng} / \mathrm{ml}$

एक्य $50 \mathrm{ng} / \mathrm{ml}+\mathrm{RAGE} \mathrm{Ab}$

$50 \mathrm{ng} / \mathrm{ml}+\mathrm{TLR} \mathrm{Ab}$

Figure 4. (A and C) High mobility group box 1 (HMGB1)-induced upregulation of receptor for advanced glycation end products (RAGE) and Toll-like receptor (TLR) 2/4 protein expression detected by western blot analysis. The MSCs were maintained in OSI complete medium alone (A, lane a) or with HMGB1 (A, lanes b-d: $12.5,25$ and $50 \mathrm{ng} / \mathrm{ml}$, respectively) for 3,5 and 7 days. (D) HMGB1-induced upregulation of RAGE and TLR2/4 mRNA expression detected by RT-qPCR. (B and

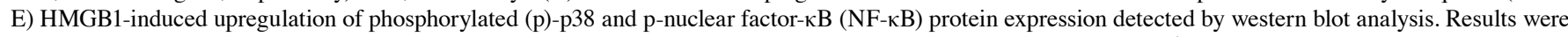
obtained from 3 independent experiments and are expressed as the means $\pm \mathrm{SD}\left(\mathrm{n}=3\right.$ in each experiment). Ab, antibody. ${ }^{*} \mathrm{P}<0.05$.

a marked decrease in expression compared to the cells treated with $50 \mathrm{ng} / \mathrm{ml}$ HMGB1 alone. By contrast, the cells treated with the NF- $\mathrm{KB}$ inhibitor exhibited a marked increase in expression compared to the cells treated with $50 \mathrm{ng} / \mathrm{ml}$ HMGB1 (Fig. 6).

\section{Discussion}

HMGB1 is a widely expressed and multifunctional inflammatory factor, the biological characteristics of which have been studied 
A
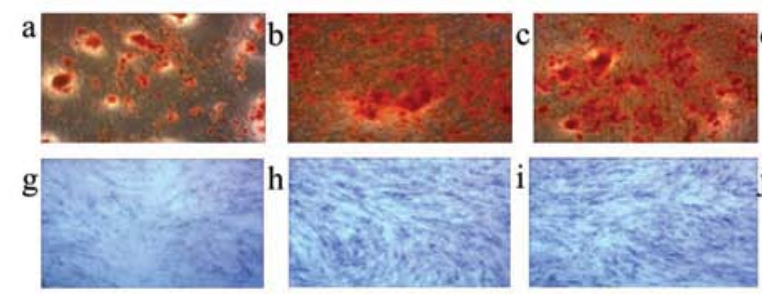
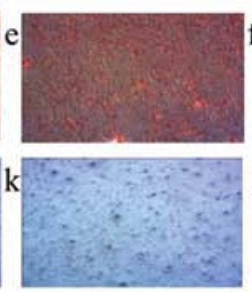

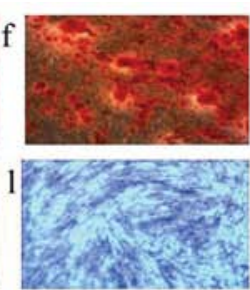

B
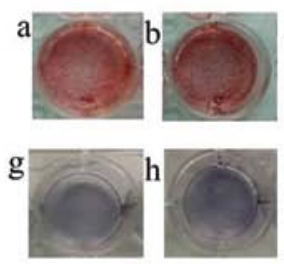
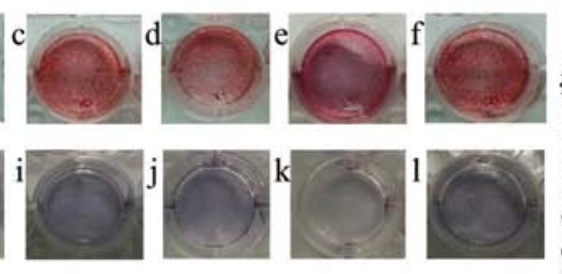

C

Alizarin red

ALP

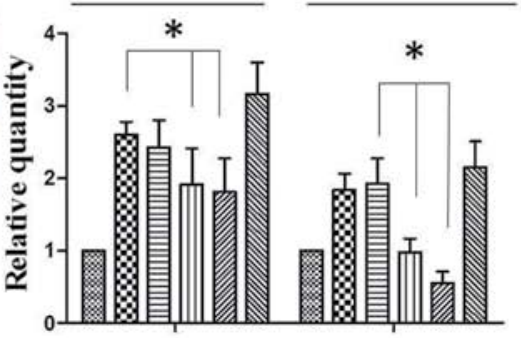

control

$50 \mathrm{ng} / \mathrm{ml}$

$50 \mathrm{ng} / \mathrm{ml}+\mathrm{RAGE} \mathrm{Ab}$

$50 \mathrm{ng} / \mathrm{ml}+\mathrm{TLR} \mathrm{Ab}$

$50 \mathrm{ng} / \mathrm{ml}+\mathrm{p} 38 \mathrm{Inh}$

$50 \mathrm{ng} / \mathrm{ml}+\mathrm{NF}-\mathrm{\kappa B}$ Inh

Figure 5. Toll-like receptor (TLR) 2/4 neutralizing antibody or p38 inhibitors inhibit the high mobility group box 1 (HMGB1)-induced osteoblastic differentiation of mesenchymal stem cells (MSCs). MSCs were maintained in standard osteoinductive (OSI) complete medium alone (A and B, panels a and g) or with HMGB1 (50 ng/ml) (A and B, panels b and h). MSCs were also maintained in OSI complete medium with HMGB1 (50 ng/ml) and receptor for advanced glycation end products (RAGE) neutralizing antibody ( $A$ and B, panels $\mathrm{c}$ and i) TLR2/4 neutralizing antibody (A and B, panels d and j), p38 inhibitors (A and B, panels e and k) or nuclear factor- $\mathrm{kB}$ (NF- $\mathrm{kB}$ ) inhibitors (A and B, panels $f$ and l). Cells were treated with alizarin red stain for 14 days (A and B, panels a-f) or stained with alkaline phosphatase (ALP) stain for 7 days (A and B, panels g-1). The number of stained nodules and ALP activity in MSCs treated with or without neutralizing antibody or inhibitors were quantified $(C)$. Results were obtained from 3 independent experiments and are expressed as the means \pm SD $(n=3$ in each experiment). $\mathrm{Ab}$, antibody; Inh, inhibitor. ${ }^{*} \mathrm{P}<0.05$.

in depth. It is expressed in almost all adult tissues, and is involved in the development, maintenance and repair of connective tissue, in processes such as vasculogenesis and angiogenesis $(1,4,8,17)$, neurite outgrowth (18), hematopoietic stem cell proliferation (19), embryonic development (20), and tumorigenesis (21). Notably, MSCs suppress both innate and adaptive immune responses (22). In the present study, we demonstrated that HMGB1 significantly promoted the migration of MSCs through the p38 MAPK signaling pathway. Additionally, HMGB1 promoted the osteoblastic differentiation of MSCs, and increased the gene and protein expression levels of RAGE and TLR2/4, which bind with HMGB1. The downstream signaling pathways p38 MAPK and $\mathrm{NF}-\kappa \mathrm{B}$ have previously been shown to regulate cell proliferation and differentiation (10-14). In this study, we found that these signaling pathways were activated. We therefore hypothesized that HMGB1 acts through RAGE and TLR 2/4, activating the p38 MAPK and NF- $\mathrm{B}$ signaling pathways, and thus promoting the osteoblastic differentiation of MSCs.

In this study, treatment with a neutralizing antibody against RAGE had no significant effect on MSC differentiation following treatment with HMGB1, or the activation of the p38 MAPK signaling pathway. Moreover, blockade of the p38 MAPK signaling pathway resulted in a marked decrease in the osteoblastic differentiation of MSCs. The inhibition of the TLR 2/4 receptor attenuated the HMGB1-induced MSC differentiation, but had no significant effect on $N F-\kappa B$ signaling pathway activation. The $\mathrm{NF}-\kappa \mathrm{B}$ inhibitor had no significant effect on HMGB1-induced MSC differentiation.

Taken together, the results of the present study suggest that HMGB1 promotes MSC differentiation by activating the TLR2/4 receptor and p38 MAPK signaling pathway. Given that the p38 MAPK signaling pathway is not activated through the RAGE receptor, this result was to be expected. The RAGE receptor primarily mediates the effects of immunosuppressors on immune cell activation and promotes the synthesis of cytokines (23). In the inflammatory microenvironment of a fracture, the RAGE receptor is synthesized in large quantities and is bound to HMGB1. Its main function is likely associated with the activation of other signaling pathways to promote inflammation (9), rather than the signaling pathways tested in this study. Given that the target of the NF- $\kappa B$ inhibitor (BAY 11-7082) is I $\mathrm{B}$, the data may indicate that HMGB1 induces $\mathrm{NF}-\kappa \mathrm{B}$ activation prior to $\mathrm{I} \kappa \mathrm{B}$ phosphorylation.In the present study, we did not examine the effects of HMGB1 on I $\mathrm{B}$ kinase activity, and thus the increased activity of I $\mathrm{B}$ kinase caused by HMGB1 may be likely the mechanism. This will be our next research focus.

Certain studies have described the role of these receptors in the regulation of MSCs by HMGB1 $(10,11)$. In the present study we demonstrated that activation of the p38 MAPK signaling pathway is one of the mechanisms through which HMGB1 promotes MSC migration. The c-Jun N-terminal kinase (JNK) and extracellular signal-regulated kinase (ERK) signaling pathways, which are also members of the MAPK family, are both known to significantly influence cell migration (24). However, whether these two pathways are involved in the mechanisms through which HMGB1 promotes MSC migration remains to be determined. In the present study, we demonstrted that the activation of the TLR2/4 receptor and the p38 MAPK signaling pathway is one of the mechanisms through which HMGB1 induces MSC differentiation. Although this study demonstrated that the p38 MAPK signaling pathway was not activated by the RAGE receptor, we hypothesized that there may be another type of HMGB1 receptor that activates 
A

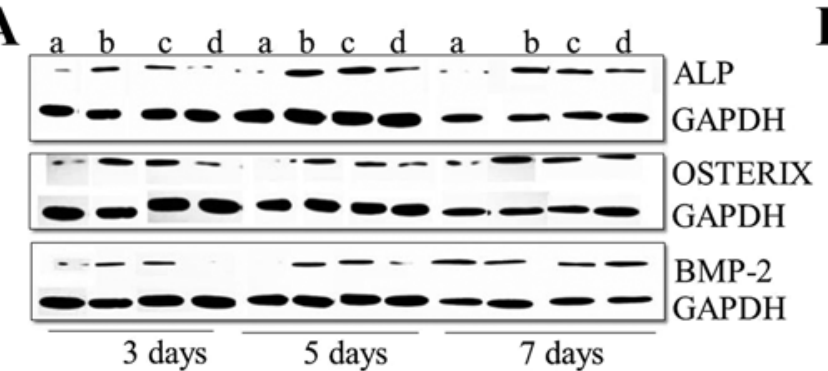

B

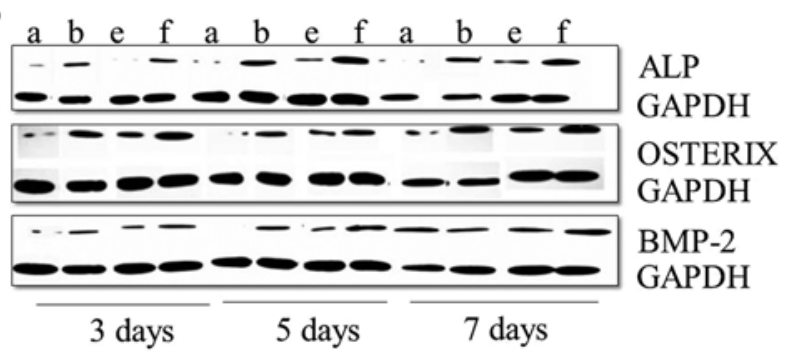

C

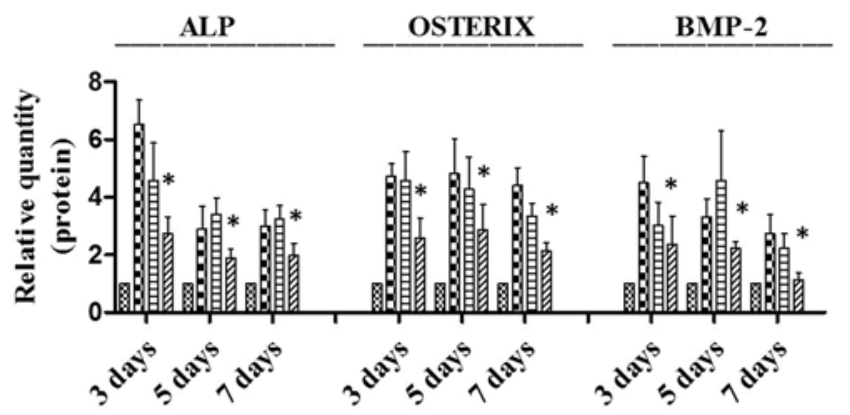

\author{
control \\ $\$ 50 \mathrm{ng} / \mathrm{ml}$ \\ 曰5 $0 \mathrm{ng} / \mathrm{ml}+\mathrm{RAGE} \mathrm{Ab}$ \\ שाת $50 \mathrm{ng} / \mathrm{ml}+\mathrm{TLR} \mathrm{Ab}$
}

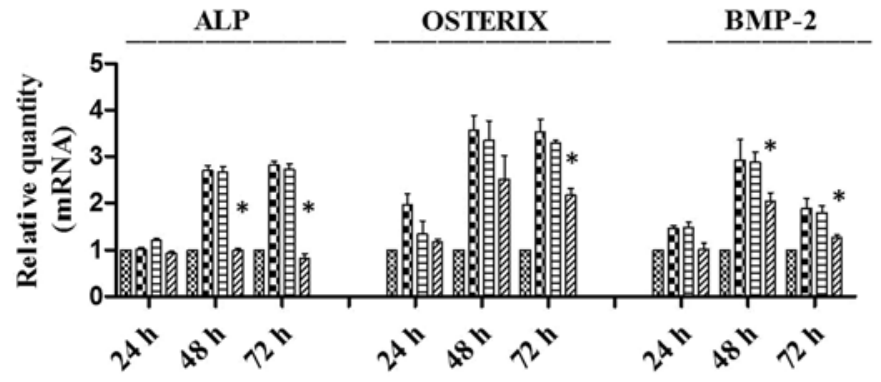

\author{
control \\ $\$ 50 \mathrm{ng} / \mathrm{ml}$ \\ 曰50 $\mathrm{ng} / \mathrm{ml}+\mathrm{RAGE} \mathrm{Ab}$ \\ III $50 \mathrm{ng} / \mathrm{ml}+\mathrm{TLR} \mathrm{Ab}$
}

D
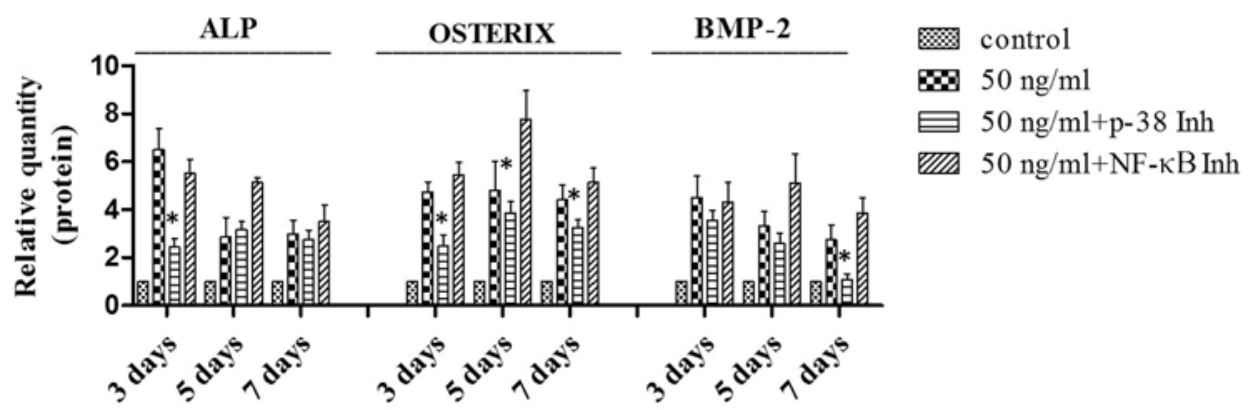

$\mathbf{E}$

F
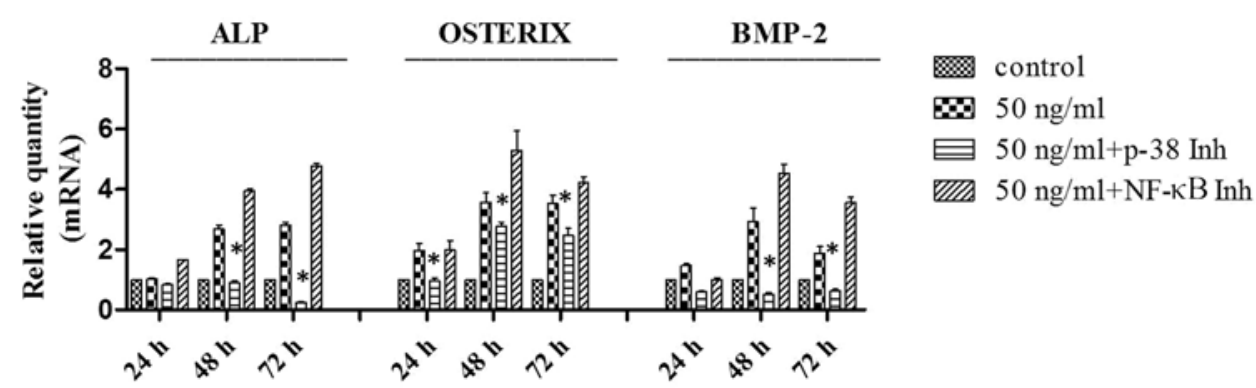

Figure 6. Toll-like receptor (TLR2/4) neutralizing antibody or p38 inhibitors inhibit the high mobility group box 1 (HMGB1)-induced upregulation of OSTERIX, alkaline phosphatase (ALP) and bone morphogenetic protein 2 (BMP-2) protein expression detected by western blot analysis and RT-qPCR. Mesenchymal stem cells (MSCs) were maintained in standard osteoinductive (OSI) complete medium alone (A and B, lane a) or with HMGB1 (50 ng/ml) (A and B, lane b). MSCs were also maintained in OSI complete medium with HMGB1 $(50 \mathrm{ng} / \mathrm{ml})$ and receptor for advanced glycation end products (RAGE) neutralizing antibody (A, lane c), TLR2/4 neutralizing antibody (A, lane d), p38 inhibitors (B, lane e) or nuclear factor- $\mathrm{kB}(\mathrm{NF}-\mathrm{\kappa B}$ ) inhibitors (B, lane f). The degree of osteoblastic differentiation was determined using western blot analysis (C and E) and RT-qPCR (D and F) to detect the protein and mRNA expression levels of ALP, OSTERIX and BMP-2 in MSCs. Results were obtained from 3 independent experiments and are expressed as the means $\pm \mathrm{SD}$ ( $\mathrm{n}=3$ in each experiment). Ab, antibody; Inh, inhibitor. ${ }^{*} \mathrm{P}<0.05$.

this signaling pathway, or perhaps HMGB1 may activate this pathway through signaling crosstalk. This is a worthy topic for future research. On the other hand, previous research has shown that the activation of TLR2/4 promotes the synthesis 
of interleukin (IL)-6 (25), which is also capable of regulating cell proliferation and differentiation (26). Thus, the role of IL-6 should be a key focus of subsequent research. Previous research has also shown that TLRs can inhibit stem cell differentiation (27). This inhibition likely results from the activation of different TLRs activating NF- $\kappa \mathrm{B}$ or IL-6, depending on the cell line and culture conditions used, but the actual mechanisms remain to be elucidated. Increasing evidence suggests that the Wnt signaling pathway is important in the regulation of the differentiation of various stem cell populations (28). Therefore, a potential future research could focus on whether HMGB1 influences the Wnt signaling pathway, and whether there is an HMGB1 receptor that activates this signaling pathway, which may be involved in the differentiation of MSCs.

\section{Acknowledgements}

This study was supported by a grant from the National Natural Science Foundation of China (Nos. 81271973 and 81201397), the Zhejiang Provincial Natural Science Foundation of China (No.LY15H060001; No. LY15H060002 and No. LY13H060002) and Zhejiang Medical and Health Science and Technology Plan Project (No. 2011ZDA011).

\section{References}

1. Degryse B, Bonaldi T, Scaffidi P, Müller S, Resnati M, Sanvito F, Arrigoni $\mathrm{G}$ and Bianchi ME: The high mobility group (HMG) boxes of the nuclear protein HMG1 induce chemotaxis and cytoskeleton reorganization in rat smooth muscle cells. J Cell Biol 152: 1197-1206, 2001.

2. Palumbo R, Sampaolesi M, De Marchis F, Tonlorenzi R, Colombetti S, Mondino A, Cossu G and Bianchi ME: Extracellular HMGB1, a signal of tissue damage, induces mesoangioblast migration and proliferation. J Cell Biol 164: 441-449, 2004.

3. Andersson U, Erlandsson-Harris H, Yang H and Tracey KJ: HMGB1 as a DNA-binding cytokine. J Leukoc Biol 72 1084-1091, 2002.

4. Yang H, Wang H, Czura CJ and Tracey KJ: HMGB1 as a cytokine and therapeutic target. J Endotoxin Res 8: 469-472, 2002.

5. Granero-Moltó F, Weis JA, Miga MI, Landis B, Myers TJ, O'Rear L, Longobardi L, Jansen ED, Mortlock DP and Spagnoli A: Regenerative effects of transplanted mesenchymal stem cells in fracture healing. Stem Cells 27: 1887-1898, 2009.

6. Glass GE, Chan JK, Freidin A, Feldmann M, Horwood NJ and Nanchahal J: TNF-alpha promotes fracture repair by augmenting the recruitment and differentiation of muscle-derived stromal cells. Proc Natl Acad Sci USA 108: 1585-1590, 2011.

7. Marsell R and Einhorn TA: The biology of fracture healing. Injury 42: 551-555, 2011.

8. Naglova $\mathrm{H}$ and Bucova M: HMGB1 and its physiological and pathological roles. Bratisl Lek Listy 113: 163-171, 2012.

9. Meng E, Guo Z, Wang H, Jin J, Wang J, Wang H, Wu C and Wang L: High mobility group box 1 protein inhibits the proliferation of human mesenchymal stem cells and promotes their migration and differentiation along osteoblastic pathway. Stem Cells Dev 17: 805-813, 2008.

10. Park JS, Svetkauskaite D, He Q, Kim JY, Strassheim D, Ishizaka A and Abraham E: Involvement of toll-like receptors 2 and 4 in cellular activation by high mobility group box 1 protein. J Biol Chem 279: 7370-7377, 2004.
11. Nakajima $\mathrm{Y}$, Inagaki $\mathrm{Y}$, Kido $\mathrm{J}$ and Nagata T: Advanced glycation end products increase expression of S100A8 and A9 via RAGE-MAPK in rat dental pulp cells. Oral Dis 21: 328-334 2015

12. Hu Y, Chan E, Wang SX and Li B: Activation of p38 mitogen-activated protein kinase is required for osteoblast differentiation. Endocrinology 144: 2068-2074, 2003.

13. Chang CP, Su YC, Lee PH and Lei HY: Targeting NFKB by autophagy to polarize hepatoma-associated macrophage differentiation. Autophagy 9: 619-621, 2013.

14. Delhalle S, Blasius R, Dicato M and Diederich M: A beginner's guide to NF-kappaB signaling pathways. Ann N Y Acad Sci 1030: 1-13, 2004.

15. Wang H, Vishnubhakat JM, Bloom O, Zhang M, Ombrellino M, Sama A and Tracey KJ: Proinflammatory cytokines (tumor necrosis factor and interleukin 1) stimulate release of high mobility group protein-1 by pituicytes. Surgery 126: 389-392, 1999.

16. Guo Z, Li H, Li X, Yu X, Wang H, Tang P and Mao N: In vitro characteristics and in vivo immunosuppressive activity of compact bone-derived murine mesenchymal progenitor cells. Stem Cells 24: 992-1000, 2006

17. Yuk JM, Yang CS, Shin DM, Kim KK, Lee SK, Song YJ, Lee HM, Cho $\mathrm{CH}$, Jeon BH and Jo EK: A dual regulatory role of apurinic/apyrimidinic endonuclease 1/redox factor-1 in HMGB1-induced inflammatory responses. Antioxid Redox Signal 11: 575-588, 2009.

18. Kim JB, Sig Choi J, Yu YM, Nam K, Piao CS, Kim SW, Lee MH, Han PL, Park JS and Lee JK: HMGB1, a novel cytokine-like mediator linking acute neuronal death and delayed neuroinflammation in the postischemic brain. J Neurosci 26: 6413-6421, 2006.

19. Wang XB, Chen X, Song KD, Wang J, Yao W, Liu HL and Sun ZM: Effects of HMGB1 on human cord blood CD34(+) hematopoietic stem cells proliferation and differentiation in vitro. Zhonghua Xue Ye Xue Za Zhi 31: 88-91, 2010 (In Chinese).

20. Polanská E, Dobšáková Z, Dvořáčková M, Fajkus J and Štros M: HMGB1 gene knockout in mouse embryonic fibroblasts results in reduced telomerase activity and telomere dysfunction. Chromosoma 121: 419-431, 2012.

21. Tang Q, Li J, Zhu H, Li P, Zou Z and Xiao Y: Hmgb1-IL-23IL-17-IL-6-Stat3 axis promotes tumor growth in murine models of melanoma. Mediators Inflamm 2013: 713859, 2013.

22. Bianchi ME and Manfredi AA: High-mobility group box 1 (HMGB1) protein at the crossroads between innate and adaptive immunity. Immunol Rev 220: 35-46, 2007.

23. Sun W, Jiao Y, Cui B, Gao X, Xia Y and Zhao Y: Immune complexes activate human endothelium involving the cell-signaling HMGB1-RAGE axis in the pathogenesis of lupus vasculitis. Lab Invest 93: 626-638, 2013

24. Zhang M, Sun L, Wang X, Chen S, Jia Q, Liu N, Chen Y, Kong Y, Zhang L and Zhang AL: Activin B promotes BM-MSC-mediated cutaneous wound healing by regulating cell migration via the JNK-ERK signaling pathway. Cell Transplant 23: 1061-1073, 2014.

25. Akira S, Hirano T, Taga T and Kishimoto T: Biology of multifunctional cytokines: IL 6 and related molecules (IL 1 and TNF). FASEB J 4: 2860-2867, 1990.

26. Schilling D, Thomas K, Nixdorff K, Vogel SN and Fenton MJ: Toll-like receptor 4 and Toll-IL-1 receptor domain-containing adapter protein (TIRAP)/myeloid differentiation protein 88 adapter-like (Mal) contribute to maximal IL-6 expression in macrophages. J Immunol 169: 5874-5880, 2002.

27. Pevsner-Fischer M, Morad V, Cohen-Sfady M, Rousso-Noori L, Zanin-Zhorov A, Cohen S, Cohen IR and Zipori D: Toll-like receptors and their ligands control mesenchymal stem cell functions. Blood 109: 1422-1432, 2007.

28. Liu Y, Han D, Wang L and Feng H: Down-regulation of Wnt10a affects odontogenesis and proliferation in mesenchymal cells. Biochem Biophys Res Commun 434: 717-721, 2013. 